\title{
Circular ring shaped ultra-wideband metamaterial absorber with polarization insensitivity for energy harvesting
}

\author{
John Bosco John Paul, Aruldas Shobha Rekh \\ Department of Electronics and Communication Engineering, Karunya Institute of Technology and Sciences, Coimbatore, India
}

\begin{tabular}{|c|c|}
\hline Article Info & ABSTRACT \\
\hline Article history: & A circular ring-shaped metamaterial (CRM) absorber was designed to harvest \\
\hline Received Jul & radio frequency $(\mathrm{RF})$ energy in the ultra-wideband (UWB) frequency band \\
\hline & applications. The proposed metamaterial unit cell features a circular shaped \\
\hline 6, 2021 & structure, with rectangular strip lines connected in the form of a cross leaving \\
\hline Accepted Oct 4, 2021 & $\begin{array}{l}\text { a square shaped slot at center. The unit cell dimensions are } 15 \times 15 \times 1.6 \mathrm{~mm} \text {. } \\
\text { The absorber was etched on a low cost FR } 4 \text { substrate having a dielectric }\end{array}$ \\
\hline Keywords: & $\begin{array}{l}\text { constant of } 4.4 \text {. Ansys high trequency structure simulator (HFSS) sottware } \\
\text { was used for simulation and the analysis were carried out for unit cell, } 2 \times 2 \text {, }\end{array}$ \\
\hline Absorptivity & $3 \times 3$, and $4 \times 4$ array structures. The absorber parameters plotted are absorption \\
\hline Energy harvesting & ristics. \\
\hline Metamaterial & ameters ( $\mu \mathrm{eff})$ and (ceff) are also retrieved from the absorber parameters \\
\hline Polarization insensitivity & and analyzed. From the analysis, the values ( $\mu \mathrm{eft})$ and ( $\varepsilon \mathrm{ett})$ were found to be \\
\hline Ultra-wideband & $\begin{array}{l}\text { negative, leaving retractive index also negative }(n<0) \text {, which proved the } \\
\text { metamaterial property. The proposed CRM absorber showed good absorption }\end{array}$ \\
\hline & characteristics of more than $80 \%$ and also metamaterial property in the entire \\
\hline & $\begin{array}{l}\text { UWB band }(4-13 \mathrm{GHz}) \text {. Hence the absorber proves to be a good candidate in } \\
\text { powering low power sensors/microcontrollers for internet of things (IoT) } \\
\text { applications. }\end{array}$ \\
\hline
\end{tabular}

This is an open access article under the CC BY-SA license.

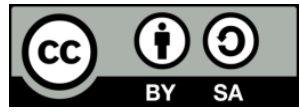

\section{Corresponding Author:}

John Bosco John Paul

Department of Electronics and Communication Engineering, Karunya Institute of Technology and Sciences Karunya Nagar, Coimbatore 641114, Tamil Nadu, India

Email: johnpaul49@gmail.com, johnpaul@karunya.edu

\section{INTRODUCTION}

Energy harvesting from renewable energy sources have become very vital in recent years. Different ways of harvesting energy from natural resources like wind, solar, vibration, thermal attracted a lot of attention in recent years. One such freely available energy source is electromagnetic (EM) waves. Due to the rapid development of wireless communication systems, EM waves are found everywhere around us starting from mobile towers, radio towers, mobile phones, wireless modems, Wi-Fi, Bluetooth devices. Harvesting energy from EM waves garnered much attention because of its advantage to power low power electronic devices. Several kinds of harvesting methods and techniques have been developed by researchers over the years to harvest energy from ubiquitous EM waves. Properly designed energy absorbers can absorb EM energy from the most widely used frequency bands like, $1800 \mathrm{MHz}, 1900 \mathrm{MHz}, 2.4 \mathrm{GHz}, 5.8 \mathrm{GHz}$ and ultra-wideband (UWB), and can develop sufficient energy to power internet of things (IoT) devices. Metamaterial absorbers find their applications in stealth technology, energy harvesters, and cloaking [1], [2]. Metamaterial absorbers are usually developed with a single, dual, triple and multi band absorption characteristics [3]-[5]. These metamaterial absorbers are designed and tuned based on the lumped parameters [6]-[8]. Different metamaterial absorbers have been developed to suit specific applications, for instance, a microwave metamaterial is developed with frequency tunability for sensing applications [9], low-cost microwave multiband [10], 
wideband [11]-[13], polarization insensitive absorbers [14], [15] are developed with ultra-thin absorbers [16] for electromagnetic interference (EMI)/electromagnetic compability (EMC) applications and stealth technology for military applications [17]. Designing EM absorbers which can harvest in the entire UWB band can be very useful for battery less applications.

In recent times due to the development of wireless communication systems and the massive quantity of available information, the data to be processed is high. To cope with this several communication systems have incorporated UWB antennas for automotive radar applications [18] and solar cell applications [19]. In the proposed work, metamaterial-based circular ring-shaped metamaterial (CRM) absorber was designed for UWB applications. The absorber can absorb EM energy in the entire UWB band from 3.1 to $10.6 \mathrm{GHz}$. An array of $2 \times 2,3 \times 3$ and $4 \times 4$ structures were also considered in the work. The metamaterial unit cell consists of a circular ring-shaped structure with four rectangular strip lines arranged in the form of a cross leaving a square shaped slot 'a2' at its center. The designed metamaterial absorber was also insensitive to the various polarization angles, which further improved the absorption characteristics.

\section{DESIGN OF PROPOSED UNIT CELL ABSORBER}

The proposed UWB-metamaterial absorber unit cell structure is presented in Figure 1. Figure 1(a) represents the diagonal view and Figure 1(b) represents the top view of the proposed absorber. The optimal dimensions are shown in Table 1. The CRM absorber was printed on a FR4 substrate having thickness of 1.6 $\mathrm{mm}$. The dielectric constant and loss tangent of the FR4 are 4.4 and 0.02 . The unit cell absorber consists of a circular ring-shaped resonator with cross shaped strips leaving a square shaped slot at the center, etched on a metallic copper ground plane separated by a dielectric FR4 substrate. This arrangement aids to absorb all the incident radiations and also helps to tune individually the parameters permeability $(\mu)$ and permittivity $(\mathcal{E})$.

Table 1. Optimal measurements of the absorber

\begin{tabular}{cc}
\hline Parameter & Values $(\mathrm{mm})$ \\
\hline $\mathrm{a}$ & 15 \\
$\mathrm{a} 1$ & 1.6 \\
$\mathrm{a} 2$ & 1.2 \\
Ro & 7 \\
Rin & 5.9 \\
$\mathrm{~g}$ & 1 \\
$\mathrm{t}$ & 1.6 \\
\hline
\end{tabular}

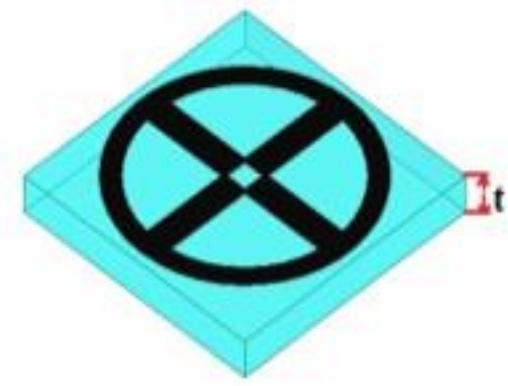

(a)

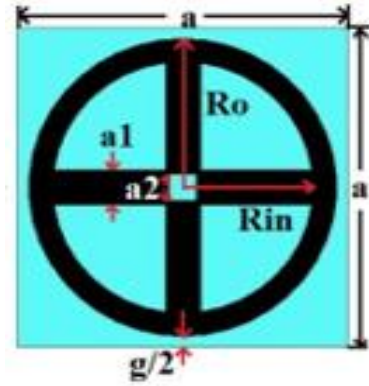

(b)

Figure 1. Metamaterial unit cell absorber: (a) diagonal view and (b) top view

The absorption spectrum $\mathrm{A}(\omega)$ of a metamaterial absorber can be evaluated with the help of transmittance $T(\omega)$ and reflectance $R(\omega)$ [20]. Transmittance $T(\omega)$ and reflectance $R(\omega)$ can be calculated using scattering parameters S11 and S21 parameters using (1) to (3) [21].

$$
\begin{aligned}
& R(\omega)=\left|S_{11}\right|^{2} \\
& T(\omega)=\left|S_{21}\right|^{2} \\
& A(\omega)=[1-R(\omega)-T(\omega)]
\end{aligned}
$$


Similarly, to comprehend the absorbers metamaterial characteristics, the values of relative permeability ( $\mu$ eff) and permittivity ( $\varepsilon$ eff) can be retrieved from the scattering parameters, which was done in two steps.

Step 1: S parameters [22], [23] can be related to refractive index (n) and impedance (z) values. The $S$ parameters can be written as (4) and (5). Solving (4) and (5) we get (6) and (7).

$$
\begin{aligned}
& \mathrm{S}_{11}=\frac{\mathrm{R}_{01}\left(1-\mathrm{e}^{\mathrm{i} 2 \mathrm{nk}_{0} \mathrm{~d}}\right)}{1-\mathrm{R}_{01}^{2} \mathrm{e}^{\mathrm{i} 2 \mathrm{nk}_{0} \mathrm{~d}}} \\
& \mathrm{~S}_{21}=\frac{\left(1-\mathrm{R}_{01}^{2}\right) \mathrm{e}^{\mathrm{i} 2 \mathrm{nk}_{0} \mathrm{~d}}}{1-\mathrm{R}_{01}^{2} \mathrm{e}^{\mathrm{i} 2 \mathrm{nk}_{0} \mathrm{~d}}} \\
& \mathrm{z}= \pm \sqrt{\frac{\left(1+\mathrm{S}_{11}\right)^{2}-\mathrm{S}_{21}^{2}}{\left(1-\mathrm{S}_{11}\right)^{2}-\mathrm{S}_{21}^{2}}} \\
& \mathrm{n}=\frac{1}{k_{0} d}\left[\left\{\left[\ln \left(e^{i n k_{0} d}\right)\right]^{\prime \prime}+2 m \pi\right\}-i\left[\ln \left(e^{i n k_{0} d}\right)\right]^{\prime}\right]
\end{aligned}
$$

Here $R_{01}$ is $Z-1 / Z+1$ [18], $n$ represents refractive index, $Z$ represents impedance, $K_{0}$ represents wave number, $d$ represents the maximum length of the unit cell, ' $m$ ' represents the branch due to the periodicity of the sinusoidal function, $E$ and $H$ represents electric and magnetic field components respectively.

Step 2: The refractive index $(n)$ and impedance $(z)$ consecutively are also related to effective permittivity (ceff) and permeability ( $\mu$ eff) by (8) and (9) [24], [25].

$$
\begin{aligned}
& \varepsilon_{\text {eff }}=\frac{n}{z} \\
& \mu_{\text {eff }}=n z
\end{aligned}
$$

\section{PARAMETRIC STUDY}

For the proposed CRM absorber, two geometrical parameters are considered for the parametric study. They are the outer radius (Ro) and gap (g) between two neighbouring circular rings while the remaining parameters are unchanged as listed in Table 1. After the parametric study, the optimal values of Ro and $g$ are considered for further evaluation with different number of unit cells.

\subsection{Circular ring radius (Ro) variation}

The effect of outer circle's radius (Ro) variation is analysed for the proposed CRM absorber. The various values of Ro ranging from $\mathrm{Ro}=6 \mathrm{~mm}, 7 \mathrm{~mm}, 8 \mathrm{~mm}$ and $9 \mathrm{~mm}$ are considered for the analysis. The comparative analysis of absorption vs frequency plots is shown in the Figure 2 . As Ro=6 mm, the absorption peak reaches unity between $10.5-13 \mathrm{GHz}$. When $\mathrm{Ro}=7 \mathrm{~mm}$ the absorption peak reaches unity between 8-10.5 GHz. At Ro=8 mm the absorption peak occurs unity $(100 \%)$ between $6.5-9 \mathrm{GHz}$ and at Ro=9 mm the absorption peak occurs unity at 5.5-7.5 GHz. From the Figure 2 data, it is understood that as the value of outer Ro increases, the resonant curves shift towards the lower resonant frequency and the absorption curve width decreases from a maximum of $2.5 \mathrm{GHz}$ to a minimum of $2 \mathrm{GHz}$. For the optimum value of $\mathrm{Ro}=7 \mathrm{~mm}$, the absorber shows good absorption characteristics of more than $85 \%$ between $4 \mathrm{GHz}$ to $13 \mathrm{GHz}$.

\subsection{Gap between the circular rings (g) variation}

Similarly, the effect of absorption due to the variation of gap (g) between two successive circular rings has been observed for various values of $g=1 \mathrm{~mm}, 2 \mathrm{~mm}$, and $3 \mathrm{~mm}$. The comparative analysis for $g$ variation is presented in the following Figure 3. Figure 3 illustrates that as the value of $g$ increases $(\mathrm{g}=1 \mathrm{~mm}, 2 \mathrm{~mm}$, and $3 \mathrm{~mm}$ ) there is a slight frequency shift to the right. For the optimum value of $\mathrm{g}=1 \mathrm{~mm}$, the proposed absorber has good absorption of more than $85 \%$ in frequency band between $3.1 \mathrm{GHz}$ to $13 \mathrm{GHz}$.

\subsection{Variation in number of unit cells $(\mathbf{N})$}

After the parametric study, the optimum values $\mathrm{Ro}=7 \mathrm{~mm}$ and $\mathrm{g}=1 \mathrm{~mm}$ are considered for the proposed unit cell and the remaining dimensions are considered as per Table 1. The absorber analysis was also extended for the array structures starting from $2 \times 2,3 \times 3,4 \times 4$ as shown in Figure $4(a)-(d)$. The plots representing the 
comparative analyses for unit cell and array structures $(2 \times 2,3 \times 3$, and $4 \times 4)$ are shown in the Figure 5 . Figure 5 represents that for various array structures, the corresponding absorption vs frequency response plots remain the same. The absorption is maintained above $80 \%$ throughout the frequency band between 3.1 to $13 \mathrm{GHz}$.

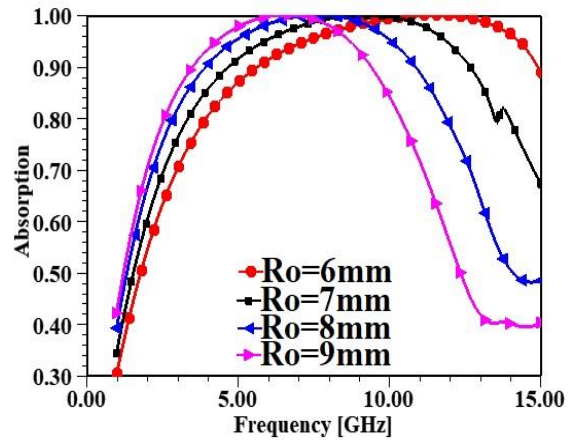

Figure 2. Absorption vs frequency curve comparison for Ro variation

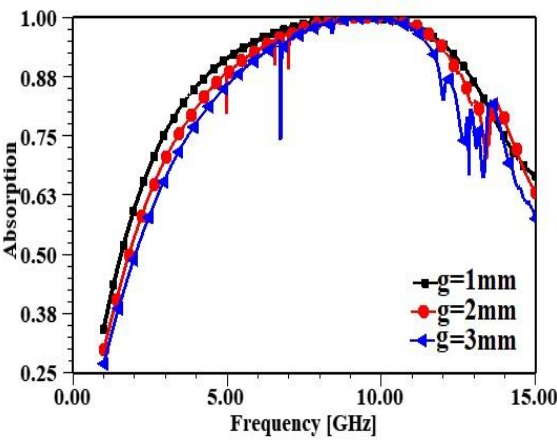

Figure 3. Absorption vs frequency curve comparison for $\mathrm{g}$ variation

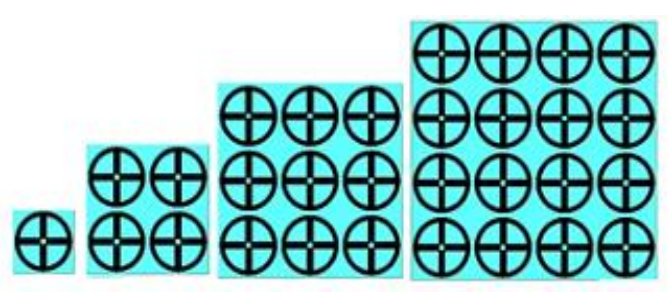

(a) (b)

(c)

(d)

Figure 4. Array structures: (a) unit cell CRM absorber, (b) 2x2 array, (c) 3x3 array, and (d) 4x4 array

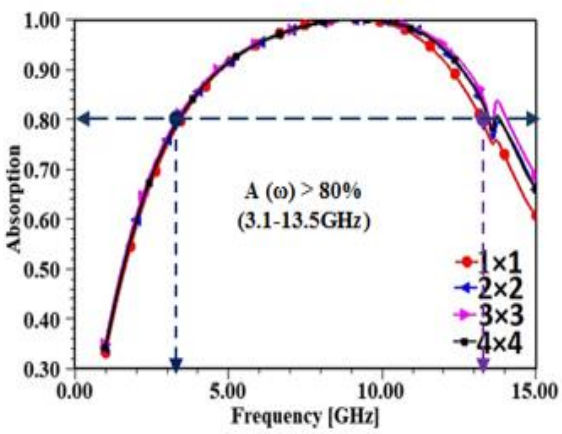

Figure 5. Comparative analysis for different number of unit cells

\section{SIMULATED RESULTS AND DISCUSSION}

In this section, the simulated results of the proposed absorber are discussed. To analyze the proposed absorbers performance (unit cell), its absorption characteristics, reflection characteristics, electric field (E) distribution, surface current ( $\mathrm{Jvol}$ ) distribution, polarization insensitivity behavior is conversed in detail.

\subsection{Absorption and reflection characteristics}

The unit cell structure shown in Figure 1 is designed using Ansys high frequency structure simulator (HFSS) 19.2v. Figure 6 represents the simulation setup for the absorber. The incident wave propagation is along the Z-axis which is perpendicular to the metamaterial absorber and the boundaries along the $\mathrm{X}$-axis and $\mathrm{Y}$-axis is made perfect electric (PEC) and perfect magnetic (PMC) respectively. Initially a unit cell is considered for analysis. The absorption characteristics can be computed from its scattering parameters using 
equations [1]-[3]. Similarly, the absorption characteristics can be extracted through finite element method (FEM) simulations.

From the Figure 6, it is observed that proposed metamaterial absorber is having absorption above $80 \%$ in the UWB region, especially from 3.1 to $13 \mathrm{GHz}$ and the absorption is above $90 \%$ for the frequencies from 5.5 to $12 \mathrm{GHz}$. After simulating the absorption and reflection plots, the effective permeability (ceff) and effective permeability ( $\mu$ eff) parameters are analyzed for its metamaterial characteristics. The $\varepsilon$ eff and $\mu$ eff parameters can be computed using the equations [4]-[9] or can be extracted from the absorption and refection plots using matrix laboratory (MATLAB) code. In the proposed work the values are extracted and the extracted values of $\varepsilon$ eff, $\mu$ eff, $\mathrm{n}$ and $\mathrm{z}$ are shown in the Figure 7. From Figure 7(a) data, it can be realized that the effective permittivity (eeff) and permeability ( $\mu$ eff) lies mostly in the negative region from 4 to $13.5 \mathrm{GHz}$ and from Figure 7(b) data, the values of the refractive index $(n)$ are negative $(n<0)$, and the value of impedance $(\mathrm{z})$ is almost $1(\mathrm{z}=1)$ from 4 to $13 \mathrm{GHz}$. From the above graphs, we can infer on the two cases; as the value of $\mathrm{n}$ is negative, it proves that the proposed absorber characteristics lies in the fourth quadrant $(n<0)$. As the value of $\mathrm{n}$ lies in the negative region, this shows that the absorber is a perfect absorber which describes its metamaterial property in the region from 4 to $13 \mathrm{GHz}$ representing left-handed materials (LHM). Similarly, the value of impedance (z) is equal to unity, which shows that the impedance of the absorber is matched with the free space impedance.

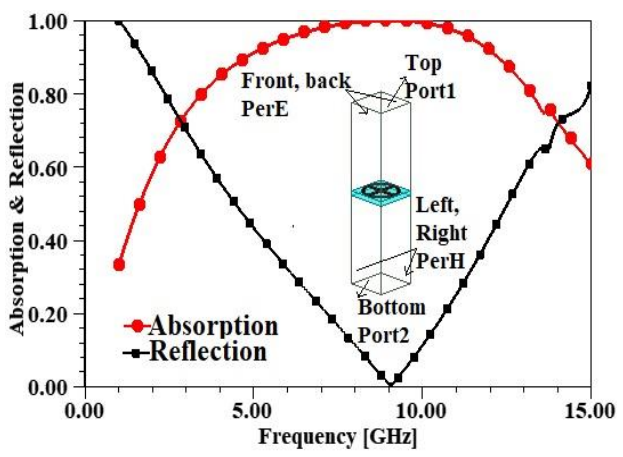

Figure 6. Unit cell analysis setup and reflection and absorption vs frequency curve

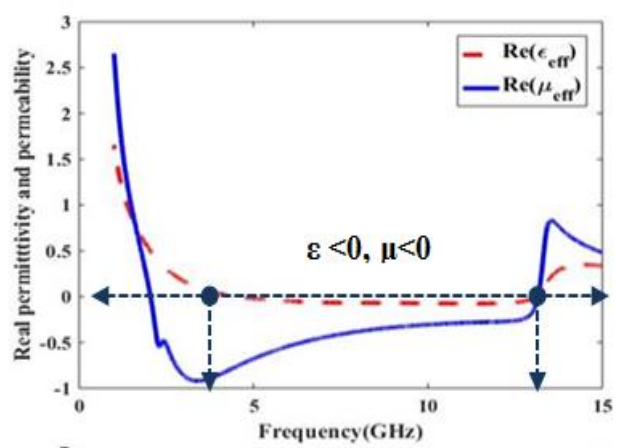

(a)

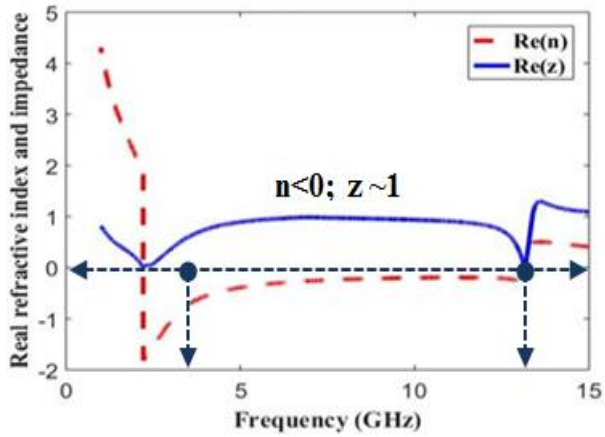

(b)

Figure 7. Extracted values on (a) plots of effective permittivity (Eeff) and permeability ( $\mu$ eff) and (b) plots of refractive index (n) and impedance $(\mathrm{z})$

\subsection{Electric field (E) and surface current distribution ( $\left.\mathbf{J}_{\text {surf }}\right)$}

The unit cell analysis is extended to realize the electric field and surface current distributions for a $4 \times 4$ array. The electric field (E) and surface current distribution ( $\left.\mathrm{J}_{\text {surf }}\right)$ for a $4 \times 4$ CRM absorber is shown in the Figure 8. From the Figure 8 represents current distribution simulated at the center frequency of 7.5 GHz. The concentration of electric field (E) is mostly at the upper and lower conductive rings. Also, the surface current distribution $\left(\mathrm{J}_{\text {surf }}\right)$ is more concentrated at the upper conductive circular rings and maintains the same orientation in all unit cells. For energy harvesting applications, the concentration of the surface current at a specific section is more important than in a distributed manner. This helps to harvest or tap more energy at the outer rings, which in turn can improve the DC output voltage at the rectifier side. 

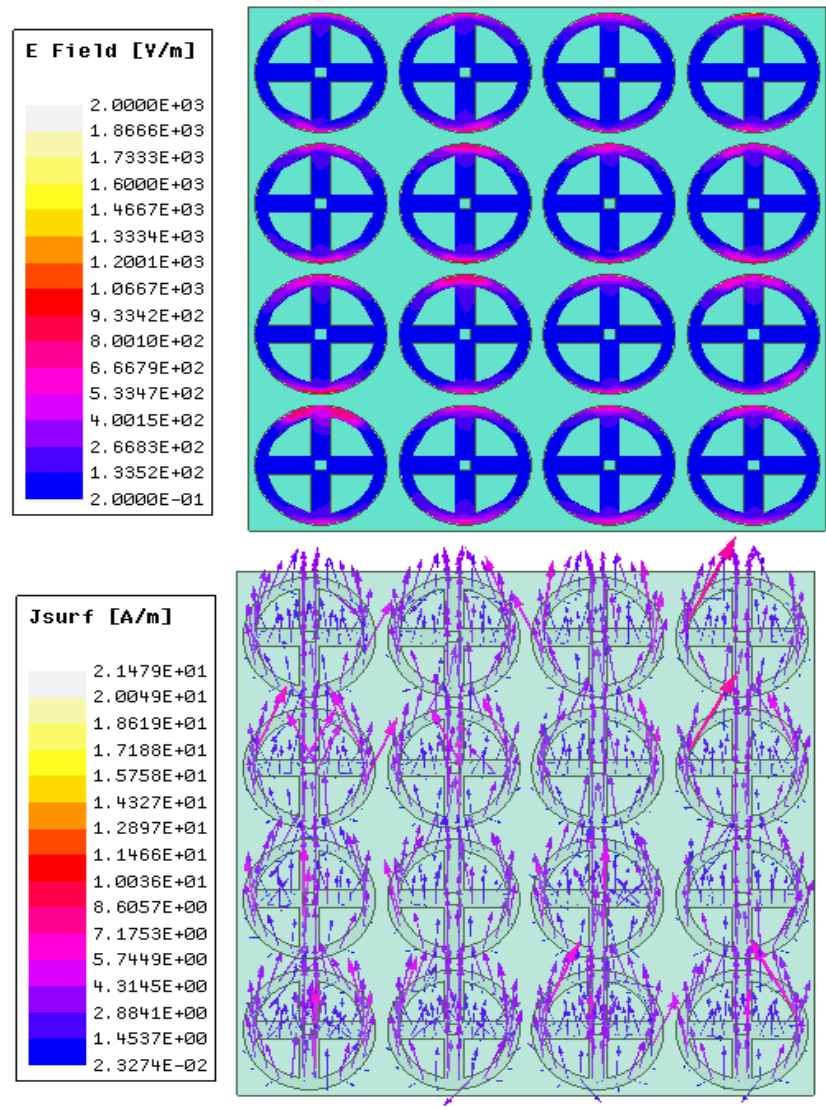

Figure 8. Simulated E-field and surface current distribution ( $\left.\mathrm{J}_{\text {surf }}\right)$ for $\mathrm{CRM}$ absorber $4 \mathrm{x} 4$ array at $7.5 \mathrm{GHz}$

\subsection{Polarization insensitivity}

The absorption curves for different values of polarization are illustrated in the Figure 9. From the figure, it can be understood, that for the various angles of $0^{0}, 30^{\circ}, 45^{\circ}, 90^{\circ}$ the absorption characteristics of the absorber shows very negligible change. This proves that the angle of incidence has almost no effect on the absorption response of the proposed CRM. From the results we can conclude that the designed CRM absorber has the advantage of polarization insensitive to different angles of incidence. The performance comparison of the present work with previous literature is presented in Table 2. Comparing with the previous works [13][16], the proposed absorber shows wide and good absorption characteristics in the UWB region (4 to $13 \mathrm{GHz}$ ). Begaud et al. [14] explained that though the absorber has good absorption characteristics compared to our work, the limitations is on the thickness $(\mathrm{t}=5 \mathrm{~mm})$ i.e., the thickness is very high compared to our proposed work $(\mathrm{t}=1.6 \mathrm{~mm})$.

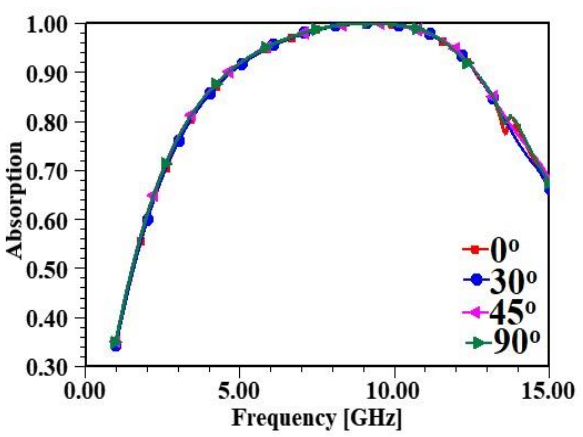

Figure 9. Absorption vs frequency curve comparison when energy is incident with different angles $\left(0^{\circ}, 30^{\circ}, 45^{\circ}, 90^{\circ}\right)$ 
Table 2. Performance comparison of proposed MTM absorber with previous works

\begin{tabular}{ccccccc}
\hline Reference & $\begin{array}{c}\text { Unit cell } \\
\text { Size }(\mathrm{mm})\end{array}$ & $\begin{array}{c}\text { Thickness of } \\
\text { dielectric } \\
\text { medium }(\mathrm{mm})\end{array}$ & $\begin{array}{c}\text { Design structure of } \\
\text { MTM }\end{array}$ & Freq (GHz) & $\begin{array}{c}\text { MTM } \\
\text { layers }\end{array}$ & $\begin{array}{c}\text { Polarisation } \\
\text { insensitivity }\end{array}$ \\
\hline$[11]$ & $16 \times 16$ & 1.5 & Concentric circular split rings & $4.6,6.8,11.3,13.4$ & Single \\
Single & No \\
{$[12]$} & $8 \times 8$ & 1 & Circular and square split rings & 12 to 16 & So & Yes \\
{$[13]$} & $20 \times 20$ & 1.6 & Crescent shaped rings & 5 & Single \\
{$[16]$} & $7.1 \times 7.1$ & 2 & Dual spit rings & $7.85-12.25$ & Multilayer & Yes \\
{$[18]$} & $10 \times 10$ & 4 & Fractal shape & $4.82-12.23$ & Multilayer & Yes \\
$\begin{array}{c}\text { Proposed } \\
\text { work }\end{array}$ & $8.4 \times 8.4$ & 5 & Concentric multi square rings & $4.5-25.4$ & Single & Yes \\
\hline
\end{tabular}

\section{CONCLUSION}

A circular ring-based metamaterial absorber with $15 \times 15 \mathrm{~mm}$ size was designed for UWB applications. Figure 6 shows that the designed metamaterial has good absorption characteristics of above $80 \%$ throughout the UWB ( 4 to $13 \mathrm{GHz}$ ) region. Figure 7 illustrates the metamaterial characteristics of the proposed absorber which shows negative refractive index $(n<0)$ throughout the UWB frequency range. The field distribution curves shown in Figure 8 illustrates, as that the current distribution is maximum concentrated at the upper conductive rings, maximum energy can be harvested which improves the maximum output DC voltage. From Figure 9 it is evident that the designed metamaterial is insensitive to various polarization angles. The designed CRM absorber showed good absorption characteristics of more than $80 \%$, with polarization insensitive behavior and hence it is a suitable candidate for harvesting RF energy to power low power sensors/microcontrollers for IoT applications.

\section{REFERENCES}

[1] Z. Yin et al., "Optically transparent and single-band metamaterial absorber based on indium-tin-oxide," International Journal of RF and Microwave Computer-Aided Engineering, vol. 29, no. 2, Feb. 2019, Art. no. e21536, doi: 10.1002/mmce.21536.

[2] Z. Ren, Y. Sun, Z. Lin, and C. Wang, "Ultra-narrow band perfect metamaterial absorber based on dielectric-metal periodic configuration," Optical Materials, vol. 89, pp. 308-315, Mar. 2019, doi: 10.1016/j.optmat.2019.01.020.

[3] D. Singh and V. M. Srivastava, "Dual resonance shorted stub circular rings metamaterial absorber," AEU-International Journal of Electronics and Communications, vol. 83, pp. 58-66, Jan. 2018, doi: 10.1016/j.aeue.2017.08.034.

[4] F. S. Jafari, M. Naderi, A. Hatami, and F. B. Zarrabi, "Microwave Jerusalem cross absorber by metamaterial split ring resonator load to obtain polarization independence with triple band application," AEU-International Journal of Electronics and Communications, vol. 101, pp. 138-144, Mar. 2019, doi: 10.1016/j.aeue.2019.02.002.

[5] K. P. Kaur, T. Upadhyaya, M. Palandoken, and C. Gocen, "Ultrathin dual-layer triple-band flexible microwave metamaterial absorber for energy harvesting applications," International Journal of RF and Microwave Computer-Aided Engineering, vol. 29, no. 1, Jan. 2019, Art. no. e21646, doi: 10.1002/mmce.21646.

[6] K. S. L. Al-badri, "Electromagnetic broad band absorber based on metamaterial and lumped resistance," Journal of King Saud University-Science, vol. 32, no. 1, pp. 501-506, Jan. 2020, doi: 10.1016/j.jksus.2018.07.013.

[7] M. Bağmanc1, M. Karaaslan, O. Altıntaş, F. Karadağ, E. Tetik, and M. Bakır, "Wideband metamaterial absorber based on CRRs with lumped elements for microwave energy harvesting," Journal of Microwave Power and Electromagnetic Energy, vol. 52, no. 1, pp. 45-59, Jan. 2018, doi: 10.1080/08327823.2017.1405471.

[8] H. Sheokand et al., "Transparent broadband metamaterial absorber based on resistive films," Journal of Applied Physics, vol. 122, no. 10, Sep. 2017, Art. no. 105105, doi: 10.1063/1.5001511.

[9] M. Bakır, M. Karaaslan, E. Unal, O. Akgol, and C. Sabah, "Microwave metamaterial absorber for sensing applications," OptoElectronics Review, vol. 25, no. 4, pp. 318-325, Dec. 2017, doi: 10.1016/j.opelre.2017.10.002.

[10] G. Sen and S. Das, "Frequency tunable low cost microwave absorber for EMI/EMC application," Progress In Electromagnetics Research Letters, vol. 74, pp. 47-52, 2018, doi: 10.2528/PIERL17120601.

[11] M. Moniruzzaman, M. T. Islam, G. Muhammad, M. S. J. Singh, and M. Samsuzzaman, "Quad band metamaterial absorber based on asymmetric circular split ring resonator for multiband microwave applications," Results in Physics, vol. 19, Dec. 2020, Art. no. 103467, doi: 10.1016/j.rinp.2020.103467.

[12] S. Ramya and I. Srinivasa Rao, "An ultra-thin compact wideband metamaterial absorber," Radioengineering, vol. 27, no. 2, pp. 364-372, Jun. 2018, doi: 10.13164/re.2018.0364.

[13] M. Amiri, F. Tofigh, N. Shariati, J. Lipman, and M. Abolhasan, "Wide-angle metamaterial absorber with highly insensitive absorption for TE and TM modes," Scientific Reports, vol. 10, no. 1, Dec. 2020, doi: 10.1038/s41598-020-70519-8.

[14] X. Begaud, A. Lepage, S. Varault, M. Soiron, and A. Barka, "Ultra-wideband and wide-angle microwave metamaterial absorber," Materials, vol. 11, no. 10, Oct. 2018, Art. no. 2045, doi: 10.3390/ma11102045.

[15] A. Dubey and T. Shami, "Metamaterials in electromagnetic wave absorbers," Defence Science Journal, vol. 62, no. 4, pp. 261-268, Jul. 2012, doi: 10.14429/dsj.62.1514.

[16] S. Ghosh, S. Bhattacharyya, D. Chaurasiya, and K. V. Srivastava, "An ultrawideband ultrathin metamaterial absorber based on circular split rings," IEEE Antennas and Wireless Propagation Letters, vol. 14, pp. 1172-1175, 2015, doi: 10.1109/LAWP.2015.2396302.

[17] T. Chen, S.-J. Li, X.-Y. Cao, J. Gao, and Z.-X. Guo, "Ultra-wideband and polarization-insensitive fractal perfect metamaterial absorber based on a three-dimensional fractal tree microstructure with multi-modes," Applied Physics A, vol. 125, no. 4, Art. no. 232, Apr. 2019, doi: 10.1007/s00339-019-2536-6.

[18] J. Hur, "Potential capacity factor estimates of wind generating resources for transmission planning," Renewable Energy, vol. 179, no. 1, pp. 1742-1750, Dec. 2021, doi: 10.1016/j.renene.2021.08.015. 
[19] J. Tak, E. Jeong, and J. Choi, "Metamaterial absorbers for 24-GHz automotive radar applications," Journal of Electromagnetic Waves and Applications, vol. 31, no. 6, pp. 577-593, Apr. 2017, doi: 10.1080/09205071.2017.1297257.

[20] P. Rufangura and C. Sabah, "Polarisation insensitive tunable metamaterial perfect absorber for solar cells applications," IET Optoelectronics, vol. 10, no. 6, pp. 211-216, Dec. 2016, doi: 10.1049/iet-opt.2016.0003.

[21] X. Chen, T. M. Grzegorczyk, B.-I. Wu, J. Pacheco, and J. A. Kong, "Robust method to retrieve the constitutive effective parameters of metamaterials," Physical Review E, vol. 70, no. 1, Jul. 2004, Art. no. 016608, doi: 10.1103/PhysRevE.70.016608.

[22] A. B. Numan and M. S. Sharawi, "Extraction of material parameters for metamaterials using a full-wave simulator [education column]," IEEE Antennas and Propagation Magazine, vol. 55, no. 5, pp. 202-211, Oct. 2013, doi: 10.1109/MAP.2013.6735515.

[23] Y. Zhou et al., "Ultra-wideband water-based metamaterial absorber with temperature insensitivity," Physics Letters A, vol. 383, no. 23, pp. 2739-2743, Aug. 2019, doi: 10.1016/j.physleta.2019.05.050.

[24] D. Sood and C. C. Tripathi, "A compact ultrathin ultra-wideband metamaterial microwave absorber," Journal of Microwaves, Optoelectronics and Electromagnetic Applications, vol. 16, no. 2, pp. 514-528, Apr. 2017, doi: 10.1590/2179-10742017v16i2797.

[25] Y. Shen et al., "Thermally tunable ultra-wideband metamaterial absorbers based on three-dimensional water-substrate construction," Scientific Reports, vol. 8, no. 1, Dec. 2018, Art. no. 4423, doi: 10.1038/s41598-018-22163-6.

\section{BIOGRAPHIES OF AUTHORS}
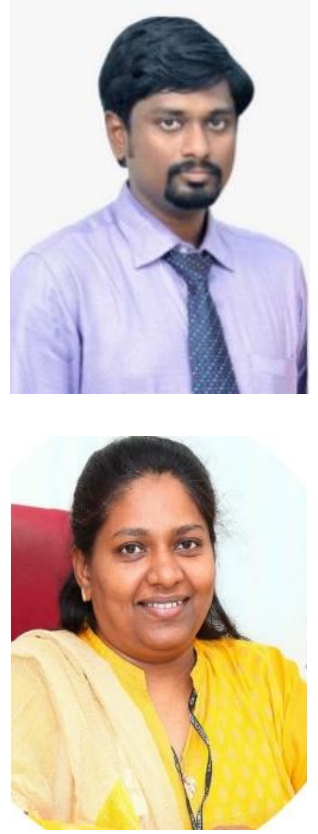

John Bosco John Paul (iD) 81 sc $\mathrm{P}$ received the B.Eng. degree in Electronics and Communication Engineering from Anna University, India in 2005, the M.E degree in Power Electronics and Drives from PSG college of Technology, India in 2009, and pursuing his $\mathrm{Ph} . \mathrm{D}$. in Karunya Institute of Technology and Sciences. Currently he is working as an Assistant Professor in the department of Electronics and Communication Engineering, Karunya Institute of technology and sciences, India. His research interests are in the area of RF Energy harvesting, Internet of things, Metamaterial absorbers and Sensor technology. He can be contacted at email: corresp-johnpaul@karunya.edu.

Aruldas Shobha Rekh (D) 8 S SC P received the B.Eng. degree in Electrical and electronics Engineering from CIT, India in 1993, and the M.E degree in Applied Electronics from PSG college of technology, India in 1997 and Ph.D. degree from PSG college of Technology, India in 2008. Currently she is working as a Professor in the Department of Electronics and Communication Engineering, Karunya Institute of technology and sciences, India. Her research interests are in the area of Internet of things, wireless sensor networks, Industry 4.0, Industrial IoT. She can be contacted at email: shobhapaulson@karunya.edu. 